\title{
Manifestaciones trombóticas en la neumonía viral por SARS-CoV-2 pacientes hospitalizados en el Hospital "Irma de Lourdes Tzanetatos", Panamá, Panamá. De marzo de 2020 a septiembre de 2020.
}

\author{
Thrombotic manifestations in viral neumonia by CoV-2-SARS \\ hospitalized patients at "Irma Lourdes Tzanetatos" Hospital, \\ Panama, Panama. March 2020 to September 2020.
}

\begin{abstract}
Lizeth Pinilla,* Sabrina Trejos, ${ }^{\ddagger}$ Olmedo Villarreal, ${ }^{\S}$ Amparo Aguilera, ${ }^{\ddagger}$ María Benavides, ${ }^{\natural}$ Ayezka Ceballos," José Chacón," Yaneth Gómez," María Escobar," Miriam González," Camilo Iturralde,* Julio Jaramillo,* Raúl Jiménez, ${ }^{\ddagger}$ Andrés Laguna," Harold Lee," Alejandra Lobán, ${ }^{\S}$ Yamileth Rodríguez, ${ }^{\natural}$ Rigoberto Samaniego, ${ }^{\S}$ Eduardo Tablas ${ }^{\ddagger}$
\end{abstract}

\section{RESUMEN}

La respuesta a la infección viral produce un estado de trombosis o hipercoagulabilidad que, unido a la inflamación de las células endoteliales, puede generar disfunción plaquetaria y predisposición a la formación de trombos que, aunque con frecuencia son más venosos, también pueden aparecer en el sistema arterial y producir infartos a cualquier nivel así como tromboembolia e hipertensión pulmonar. Estas manifestaciones han sido captadas hospitalariamente y al egreso de los pacientes detectados por SARS-CoV-2 habiendo ya cumplido el tiempo establecido de virulencia. Los criterios diagnósticos de respuesta inmunológica trombótica asociada a COVID-19 (RITAC) ayudan a seleccionar al paciente que está predispuesto a esta condición; a esto se añade que el paciente ya tiene un diagnóstico de infección por SARS-CoV-2.

Palabras clave: SARS-CoV-2, estados trombóticos, trombos, respuesta inmunológica a trombótica asociada a COVID-19.

\section{ABSTRACT}

The response to viral infection produces a prothrombotic state of hypercoagulability, united with an inflammation of endothelial cells, It can generate platelet dysfunction and predisposition to the formation of thrombus, that, although, are more frequently venous, Also, it can appear in the arterial system and cause heart attacks at any level; thromboembolism and pulmonary hypertension, as well. These manifestations have been captured hospitably and with the egress of patients detected by SARS-CoV-2. The diagnostic criteria of RITAC (abbreviation in Spanish of Thrombotic Immune Response Associated to COVID-19), help to select the patient who is predisposed to this condition; adding that the patient already has a diagnosis of SARS-CoV-2 infection.

Keywords: SARS-CoV-2, prothrombotic state, thrombus, spanish of thrombotic immune response associated to COVID-19.

\footnotetext{
* Medicina Interna.

¥ Neumología.

§ Infectología.

ๆ Medicina General.

"Psiquiatría.
}

Hospital «Irma de Lourdes Tzantetos», Panamá, Panamá.

Recibido: 28 Septiembre 2020. Aceptado para publicación: 11 Noviembre 2020.

Citar como: Pinilla L, Trejos S, Villarreal O, Aguilera A, Benavides M, Ceballos A et al. Manifestaciones trombóticas en la neumonía viral por SARS-CoV-2 pacientes hospitalizados en el Hospital «lrma de Lourdes Tzanetatos», Panamá, Panamá. De marzo de 2020 a septiembre de 2020. Rev ADM. 2020 ; 77 (6): 312-315. https://dx.doi.org/10.35366/97620

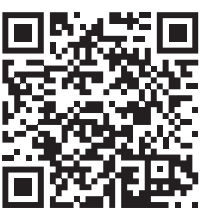




\section{INTRODUCCIÓN}

L a respuesta a la infección viral produce un estado de hipercoagulabilidad que, unido a la inflamación de las células endoteliales, puede generar disfunción plaquetaria y predisposición a la formación de trombos que, aunque con frecuencia son más venosos, también pueden aparecer en el sistema arterial y producir infartos a cualquier nivel así como tromboembolia e hipertensión pulmonares. La expresión máxima de este trastorno es la presencia de una coagulopatía similar al síndrome antifosfolípido o al establecimiento de una coagulación intravascular diseminada. ${ }^{1,2}$

Estas manifestaciones han sido captadas hospitalariamente y al egreso de los pacientes detectados por SARS-CoV-2 habiendo ya cumplido el tiempo establecido de virulencia.

La coagulopatía asociada a COVID-19 está marcada por niveles elevados de dímero $\mathrm{D}$ y fibrinógeno con anormalidades menores en el tiempo de protrombina, tiempo de tromboplastina parcial activada y recuentos de plaquetas en la etapa inicial de la infección. Los niveles elevados de dímero $\mathrm{D}$ al ingreso y un aumento longitudinal durante la hospitalización se han relacionado con peor mortalidad en COVID-19. Las complicaciones trombóticas se informaron hasta en $30 \%$ de los pacientes.

También hay evidencia emergente de trombosis en catéteres intravenosos y circuitos extracorpóreos, y eventos oclusivos vasculares arteriales, incluyendo infarto agudo de miocardio (IM), isquemia aguda de extremidades y accidente cerebrovascular en personas gravemente afectadas. También se informaron altas tasas de eventos tromboembólicos en pacientes críticos con COVID-19 a pesar de haber recibido anticoagulación profiláctica. ${ }^{3}$

Gauna y Bernava, en un artículo publicado de CorSalud, plantean la existencia de una respuesta inmunológica trombótica asociada a la COVID-19 (RITAC) donde, lejos de la posibilidad de que aparezca en individuos inmunodeprimidos, se presenta en inmunocompetentes debido a la aparición de un síndrome de activación macrofágica acompañado de una activación patológica de la trombina con la consecuente producción de múltiples episodios trombóticos. Razón por la que son muy útiles las determinaciones de ferritina y dímero D. Los criterios diagnósticos de la RITAC se muestran en la Tabla 1.4

\section{Esto se explica por medio de la fisiopatología:}

\section{Respuesta inmunológica:}

Estos pacientes presentan el síndrome de activación macrofágica (SAM). Muchos de ellos eran jóvenes o adultos jóvenes aparentemente sanos. Dicha situación no puede ser explicada por un estado de inmunodeficiencia, por el contrario, parecen haber tenido una respuesta inmunológica exagerada responsable de este final. En la fisiopatología del SAM se observa:

- Proliferación incontrolada de las células T.

- Activación excesiva de los macrófagos.

- Hipersecreción de citocinas proinflamatorias, interleucina (IL) IL-1 $\beta$, IL-6, interferón y factor de necrosis tumoral $\alpha(\mathrm{TNF} \alpha)^{1}{ }^{1}$

\section{Respuesta trombótica:}

Acompañando a la respuesta macrofágica descontrolada, en estos pacientes se aprecia una activación patológica de la trombina, por lo que se observan múltiples episodios trombóticos que van desde isquemia periférica, tromboembolismo pulmonar hasta coagulación intravascular diseminada (CID).

Estas complicaciones fueron la causa de muerte en muchos de estos enfermos. El parámetro de laboratorio más apropiado para reconocer este estado trombofílico es el dímero D elevado, ${ }^{5}$ por lo cual sugerimos su medición en todos los pacientes correspondientes al escenario $2 .^{6}$

Ante las repetidas manifestaciones en estos tiempos de pandemia, nuestra institución toma a bien presentar algunos casos.

\section{PRESENTACIÓN DEL CASO}

\section{Caso 1}

Paciente masculino de 30 años sin antecedentes personales patológicos conocidos (APP). Personal de salud, el cual estuvo hospitalizado por neumonía viral por SARSCoV-2 leve, sin cambios radiográficos en su hospitalización. Nueve días posthospitalización, acude al cuarto

Tabla 1: Criterios diagnósticos de respuesta inmunológica trombótica asociada a COVID-19.

Paciente con infección confirmada de COVID-19 con síntomas respiratorios que presente uno o más de los siguientes criterios:

1. Dímero $\mathrm{D}>1,000 \mathrm{ng} / \mathrm{mL}$

2. Ferritina $>500 \mathrm{ng} / \mathrm{mL}$

3. Disnea de rápida progresión

4. Hipoxemia refractaria

5. Fenómenos trombóticos

6. Shock 


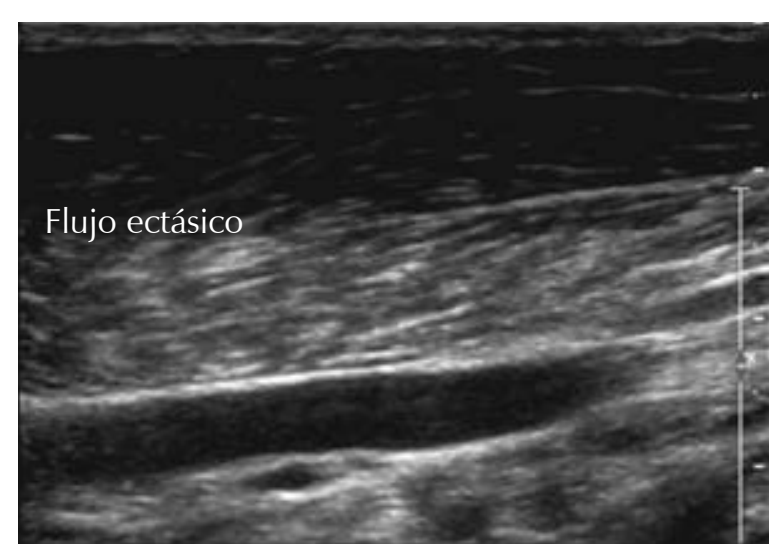

Figura 1: Ultrasonido Doppler de miembros inferiores que reporta flujo ectásico en la vena poplítea derecha.

de urgencias refiriendo historia de dos días de disnea de moderados esfuerzos sin otro síntoma. Se solicitaron marcadores trombóticos; sin embargo, en ese momento la institución no contaba con ellos. Ante la amplia sospecha, se solicita angiotomografía de tórax, la cual revela tromboembolismo pulmonar bilateral subsegmentario. El paciente fue ingresado para el manejo de insuficiencia respiratoria tipo I y la anticoagulación terapéutica con heparina de bajo peso molecular a dosis de $1 \mathrm{mg} / \mathrm{kg}$ peso. El paciente muestra evolución satisfactoria.

Se le dio egreso sin uso de oxígeno suplementario y nuevos anticoagulantes orales (NACO); apixaban $5 \mathrm{mg}$ VO cada 12 horas por tres meses. En seguimiento con clínica de anticoagulación y neumología.

\section{Caso 2}

Paciente femenino de 41 años con obesidad, sin otros antecedentes personales conocidos. Personal de salud, la cual acude vía cuarto de urgencias con historia de hace siete días detectada por PCR por SARS-CoV-2. Al día siete inicia con dificultad respiratoria súbita, náuseas, vómitos y dolor abdominal. Ante la sospecha se ingresa y se le realiza angiotomografía, la cual reporta TEP basal derecho e infiltrados difusos basales bilaterales.

Se ingresa a la paciente, se le coloca oxígeno suplementario con máscara con reservorio a $15 \mathrm{l} / \mathrm{min}$, antibióticos y anticoagulación con heparina de bajo peso molecular. Sin embargo, la paciente requirió ventilación mecánica invasiva. Con estancia en la unidad de medicina crítica de seis días. Luego pasó a sala y seis días después se le dio egreso sin oxígeno domiciliario y anticoagulación con heparina de bajo peso molecular 60 mg subcutánea cada día por tres meses. Con seguimiento con clínica de anticoagulación y neumología.

\section{Caso 3}

Paciente femenino de 33 años sin APP. Acude con historia de dolor torácico opresivo, seguido de deterioro del estado de conciencia y relajación de esfínter. Luego de un esfuerzo intenso, tos seca. Además refiere dolor articular a nivel de las interfalanges desde hace dos años.

Al examen físico se evidencia dolor en gastrocnemio derecho y fosa poplítea, por lo que se solicita ultrasonido Doppler de miembros inferiores, el cual revela flujo ectásico en la vena poplítea derecha e hisopado de PRC por SARS-CoV-2 reportado como detectado. Además, ante el antecedente de dolor articular y por ser mujer en edad productiva se solicitan pruebas reumatológicas (las mismas negativas). Cursó con buena evolución, no requirió oxígeno suplementario, y se le da egreso con heparina de bajo peso molecular a dosis de $40 \mathrm{mg} \mathrm{sc}$ cada día. Con seguimiento en clínica de anticoagulación y neumología (Figura 1).

\section{Caso 4}

Paciente masculino de 36 años con APP de SARS-CoV-2 hace un mes y medio. Además presentó fractura de fémur derecho con mala rehabilitación (deambula con muletas). En el mes de junio acudió con historia de cuatro días de hemoptisis, debilidad generalizada, asociado a dolor torácico de fuerte intensidad e hipoxemia, por lo cual acudió al cuarto de urgencias.

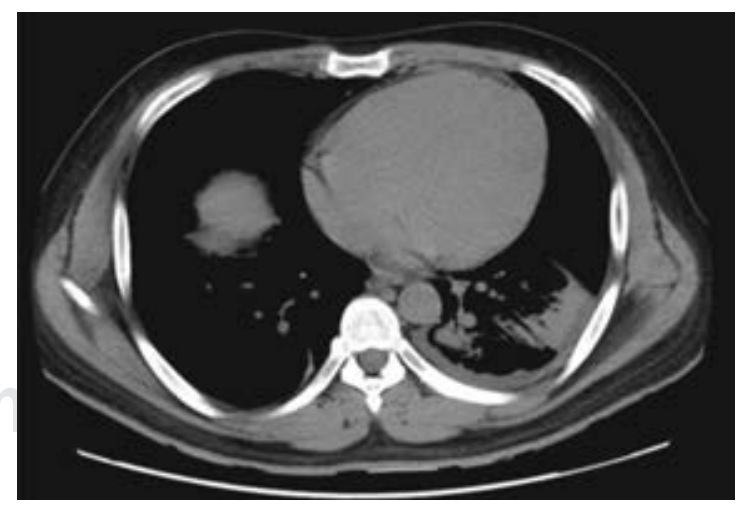

Figura 2: Angiotomografía de tórax donde se aprecia el defecto de llenado parcial, compatible con tromboembolismo pulmonar en la arteria posterior basal del lóbulo inferior derecho y en la arteria basal lateral del lóbulo inferior izquierdo. 


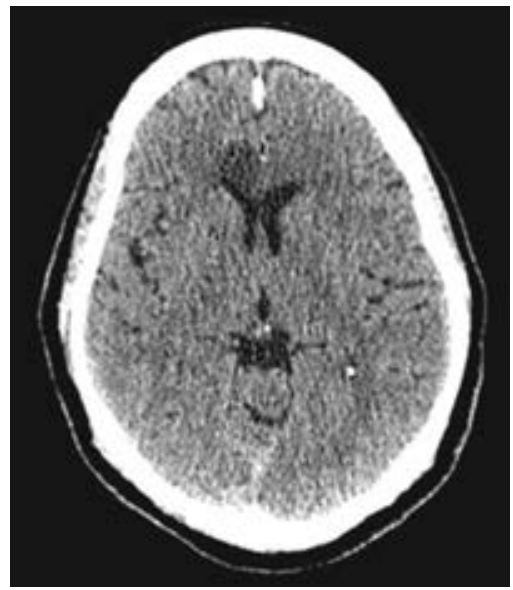

Figura 3: Tomografía cerebral simple con evidencia de isquemia cerebral aguda frontal que hace efecto de masa.

Ante la clínica se estabilizó al paciente y se solicitó angiotomografía de tórax, la cual reportó defecto de llenado parcial, compatible con tromboembolismo pulmonar en la arteria posterior basal del lóbulo inferior derecho y en la arteria basal lateral del lóbulo inferior izquierdo. Cursó con buena evolución. No requirió oxígeno domiciliario y se envió a casa con NACO. Apixaban $5 \mathrm{mg}$ vo cada 12 horas. En seguimiento con clínica de anticoagulación, medicina física y rehabilitación; y neumología (Figura 2).

\section{Caso 5}

Paciente femenino de 55 años con antecedente de neumonía viral por SARS-CoV-2 (hace un mes antes de su ingreso), hipertensión arterial controlada y obesidad. Ingresó con historia de disminución de fuerza y tono muscular, desorientación, disartria. A su ingreso ya con hemiparesia izquierda.

Se realizó tomografía cerebral simple en la que se evidencia isquemia cerebral aguda frontal. A su egreso cursó afebril, taquicárdica en dos ocasiones, luego dentro del rango de la normalidad, eupnéica, con cifras tensionales normales, tolerando dieta molida y recuperación del habla. Se le dio egreso con: simvastatina, ASA, perindopril, lamotrigina, amlodipina. Con referencia para seguimiento a: medicina familiar, neurología, neumología, medicina física y rehabilitación (Figura 3).

\section{DISCUSIÓN}

La respuesta a la infección viral por SARS-CoV-2 es sumamente variable y se extiende hasta periodos posteriores a los 14 días de la infección. Sus manifestaciones trombóticas son múltiples y pueden incrementarse en la medida en que los pacientes tengan más factores de riesgo trombóticos. Los criterios de respuesta inmunológica trombótica asociada a COVID-19 sustentan de manera asertiva el uso de anticoagulación con reducción de secuelas.

\section{CONCLUSIONES}

Las manifestaciones trombóticas por SARS-CoV-2 son sumamente esperadas, sobre todo en pacientes con riesgo. La fisiopatología nos orienta a un manejo profiláctico y a la necesidad de realizar estudios de imágenes.

Un diagnóstico previo favorece en la evolución y reducción de secuelas en los pacientes.

\section{BIBLIOGRAFÍA}

1. Mehta P, McAuley DF, Brown M, Sanchez E, Tattersall RS, Manson JJ. COVID-19: consider cytokine storm syndromes and immunosuppression. Lancet. 2020; 395 (10229): 1033-1034.

2. COVID-19. Una enfermedad multisistémica. Manifestaciones extrapulmonares de COVID-19.La fisiopatología y el impacto clínico de COVID-19 en varios sistemas de órganos. 2020.

3. Xiong TY, Redwood S, Prendergast B, Chen M. Coronaviruses and the cardiovascular system: acute and long-term implications. Eur Heart J. 2020 [En line 28 Mar 2020]: ehaa231. Available in https:// doi.org/10.1093/eurheartj/ehaa231.

4. Gauna ME, Bernava JL. Recomendaciones diagnósticas y terapéuticas ante la respuesta inmune trombótica asociada a COVID-19 (RITAC). CorSalud. 2020; 12 (1): 60-63.

5. Páramo FJ. Coagulación, dímero D y COVID-19: una reflexión de José A Páramo Hernández, presidente de la Sociedad Española de Trombosis y Hemostasia (SETH) [Internet]. Madrid: Sociedad Española de Trombosis y Hemostasia [Citado 22 Mar 2020]. Disponible en: https://www.seth.es/index.php/noticias/noticias/ noticias-de-la-seth/1588-coagulacion-dimero-d-y-covid-19.html.

6. Ministerio de Salud Argentina. Recomendaciones condicionales para el abordaje terapéutico de COVID-19 [Internet]. Buenos Aires: Ministerio de Salud Argentina; 2020 [citado 22 Mar 2020]. Disponible en: https://www.argentina.gob.ar/salud/coronavirusCOVID-19/abordaje-terapeutico.

Correspondencia:

Sabrina Trejos

E-mail: strejosgonzalez@gmail.com

Conflicto de intereses: Los autores declaran no tener ningún conflicto de intereses. 